\title{
Infektivitas Inokulan Glomus sp. dan Gigaspora sp. pada Berbagai Komposisi Media Zeolit-Arang Sekam dan Pengaruhnya Terhadap Pertumbuhan Sorgum (Sorghum bicolor)
}

\author{
Merry Prafithriasari dan Anne Nurbaity \\ Jurusan Ilmu Tanah Fakultas Pertanian Universitas Padjadjaran \\ Jl. Raya Jatinangor Km. 21 Bandung 40600 \\ Korespondensi: anurbaity@hotmail.com
}

\begin{abstract}
Infectivity of Glomus sp. and Gigaspora sp. at Different Composition of Zeolite-Rice Medium and It's Effect on Growth of Sorghum (Sorghum bicolor)

The availability of Arbuscular Mycorrhizal (AM) inoculant is very important since AM fungi has been known to be beneficial for most of terestrial plants. The use of alternative medium other than zeolite (that has been used as inoculant's medium) needs to be investigated. Experiment to determine the effect of AM fungi and medium compositions on percentage of root infection and growth of sorgum (Sorghum bicolor) was carried out at the green house of Faculty of Agriculture Padjadjaran University. The treatment was several composition of inoculant's medium which was consisted of 100 and rice charcoal. The AM fungi used were 1) Glomus sp., 2) Gigaspora sp., and 3) Glomus sp. + Gigaspora sp. Results of this experiment showed that there were no interaction effect between medium compositions with AM fungi on percentage of root infection, shoot-root ratio and height of sorghum. Different composition of medium gave significant difference on shoot-root ratio and height of sorghum. The composition of $50 \%$ zeolite $+50 \%$ rice charcoal gave the highest root infection percentage (62\%), while the highest shootroot ratio 7,01 achieved when composition of medium was $75 \%$ zeolite : $25 \%$ rice charcoal. Overall, $100 \%$ zeolit still performed better than other media for increasing the growth of sorgum, but the composition $75 \%$ zeolite: $25 \%$ rice charcoal had a potential to be used as medium for AMF propagation, either for Glomus sp. Gigaspora sp, or Glomus sp. mixed with Gigaspora sp.
\end{abstract}

Key words: Growth medium composition, Inoculant, Mycorrhiza Arbuscula.

\begin{abstract}
ABSTRAK
Pemanfaatan Fungi Mikoriza Arbuskula (FMA) sebagai pupuk hayati telah diketahui mampu meningkatkan pertumbuhan dan produktivitas tanaman. Penyediaan sumber inokulum FMA sangat berkaitan erat dengan sumber bahan baku pembawa atau media tumbuh inokulum FMA. Penelitian ini bertujuan untuk mengetahui pengaruh komposisi media tumbuh dan jenis FMA yang berbeda terhadap persentase infeksi akar dan pertumbuhan tanaman sorgum. Perlakuan komposisi media tumbuh inokulan terdiri atas beberpa komposisi zeolit dan arang sekam. Isolat FMA yang digunakan adalah: 1) Glomus sp., 2) Gigaspora sp., dan 3) Glomus sp. + Gigaspora sp. Hasil penelitian menunjukkan bahwa tidak terjadi interaksi antara komposisi media tumbuh (zeolit dan arang sekam) dengan jenis FMA terhadap peningkatan persentase infeksi akar, nisbah pupus akar dan tinggi tanaman sorgum. Secara mandiri perlakuan komposisi media memberikan pengaruh yang nyata terhadap nisbah pupus akar dan tinggi tanaman sorgum. Komposisi media tumbuh terbaik yang menghasilkan persen
\end{abstract}


infeksi akar tertinggi (62 \%) adalah komposisi media $50 \%$ zeolit + $50 \%$ arang sekam, sedangkan nisbah pupus akar tertinggi diperoleh dari komposisi media tumbuh $75 \%$ zeolit $+25 \%$ arang sekam. Walaupun kontrol (media zeolit 100\%) lebih baik di dalam meningkatkan pertumbuhan tanaman sorgum, akan tetapi komposisi $75 \%$ zeolit $+25 \%$ arang sekam memiliki potensi untuk digunakan sebagai media produksi inokulan FMA. Komposisi media ini dapat digunakan baik bagi produksi inokulan tunggal Glomus sp. atau Gigaspora sp., maupun inokulan campuran Glomus sp. + Gigaspora sp.

Kata Kunci: Komposisi media pertumbuhan, Inokulan, Mikoriza Arbsuskula.

\section{PENDAHULUAN}

Fungi Mikoriza Arbuskula (FMA) merupakan salah satu mikroorganisme yang dimanfaatkaan sebagai pupuk hayati yang dapat membantu penyediaan hara, terutama fosfat bagi tanaman melalui kolonisasi akar tanpa menimbulkan nekrosis seperti halnya terjadi pada infeksi jamur patogen (Rao, 1994). Menurut Setiadi (1999), pemanfaatan FMA dapat meningkatkan zona penyerapan dan ketersediaan hara serta resistensi terhadap cekaman air dan serangan hama penyakit. Selain itu, FMA diketahui dapat berasosiasi dengan hampir $90 \%$ tanaman dan terbukti dapat membantu pertumbuhan tanaman. Hal ini senada dengan pernyataan Smith \& Read (1997) bahwa FMA mampu bersimbiosis dengan 83 $\%$ dikotiledon, $79 \%$ monokotiledon dan hampir seluruh Gymnospermae.

Beberapa genus FMA yang umum dijumpai

adalah Glomus, Gigaspora, Acaulospora dan Scutellospora (Brundrett et al., 1996). Namun, setiap jenis FMA memiliki kemampuan yang berbeda-beda di dalam membantu meningkatkan pertumbuhan tanaman. Dengan demikian, pemilihan isolat FMA yang benar-benar kompatibel dengan tanaman yang dibudidayakan perlu dilakukan. FMA hidup bersimbiosis dengan tanaman inang yang responsif dan memiliki perakaran banyak (Simanungkalit, 2003), karena hal ini akan berpengaruh terhadap pembentukan asosiasi pada akar dan sporulasi FMA (Gunawan, 1999).

Tanaman inang yang biasa digunakan untuk perbanyakan FMA adalah sorgum karena sistem perakarannya yang baik untuk pembentukan mikoriza (Gunawan, 1999; Prematuri \& Faiqoh, 1999). Sorgum merupakan salah satu jenis tanaman serealia yang mengandung karbohidrat cukup tinggi,

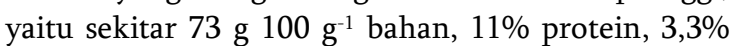
lemak, $11,2 \%$ air, dan $2,3 \%$ serat (Sirappa, 2003). Sorgum toleran terhadap kekeringan, dapat tumbuh hampir di setiap jenis tanah, serta membentuk akarakar sekunder dua kali lebih banyak, berakar dalam dan fibrous sehingga lebih efektif dalam menyerap hara dan air (Deptan, 1990). Karakteristik sorgum ini dapat meningkatkan produksi inokulan FMA karena spora FMA akan menginfeksi akar-akar sekunder dengan lebih mudah (Abdulah, et al., 2005).

Pemanfaatan FMA yang begitu luas tentunya memerlukan sumber inokulum yang banyak, sehingga penyediaan inokulan FMA menjadi sangat penting. Pada umumnya perbanyakan inokulan FMA dilakukan dengan cara kultur pot dimana FMA dengan spesies tertentu yang telah diketahui keefektifannya diinokulasikan pada tanaman inang dan medium padat yang steril. Sumber bahan media (carrier) merupakan komponen terpenting dalam perbanyakan inokulum FMA, dengan syarat dapat diperoleh dalam jumlah besar, ringan, bersifat porus, homogen dan murah (Prematuri \& Faiqoh, 1999). Media yang dapat digunakan sebagai media tumbuh dapat berupa tanah, pasir, expanded clay (agregat liat), gambut dan zeolit (Simanungkalit, 2003).

Zeolit baik digunakan sebagai media tanam karena bersifat stabil dan tidak mudah berubah atau rusak karena siraman air (Bertham, 2003). Zeolit merupakan mineral yang mampu memperbaiki produktivitas tanah dan tanaman karena bersifat basa, sehingga dapat menetralkan tanah yang bersifat asam, mengurangi daya fiksasi $\mathrm{P}$ oleh koloid tanah dan meningkatkan KTK serta aktivitas mikroorganisme dalam tanah (Deptan, 2001).

Selain zeolit, perbanyakan inokulan FMA dapat dilakukan pada media yang mengandung bahan organik. Pemanfaatan bahan organik sebagai media tumbuh inokulan FMA masih jarang digunakan, padahal dari beberapa hasil penelitian diketahui bahwa bahan organik mendukung perkembangan propagul FMA (St. John et al. 1983; Nurbaity et al. 2009). 
Sekam padi merupakan bahan organik yang berasal dari limbah pertanian yang mengandung beberapa unsur penting seperti protein kasar, lemak, serat kasar, karbon, hidrogen, oksigen dan silika. Penggunaan arang sekam sebagai media tumbuh inokulan FMA belum banyak dilakukan, diantaranya penelitian Simanungkalit dan Riyanti (1994 dalam Simanungkalit, 2003) yang menggunakan arang sekam dan pasir kuarsa dengan perbandingan 3:1 sebagai media tumbuh inokulan FMA dengan jagung sebagai tanaman inang, mampu menciptakan kondisi yang cocok untuk perkembangan Glomus fasiculatum.

Penelitian ini bertujuan untuk mengetahui potensi bahan organik berupa arang sekam padi yang dikombinasikan dengan zeolit sebagai media produksi atau carrier inokulan FMA serta sebagai alternatif solusi untuk memanfaatkan limbah pertanian, sehingga mampu meningkatkan produktivitas FMA sebagai biofertilizer.

\section{METODE PENELITIAN}

Penelitian dilakukan di rumah plastik dan Laboratorium Biologi dan Bioteknologi Tanah Jurusan Ilmu Tanah Fakultas Pertanian UNPAD Jatinangor. Percobaan menggunakan Rancangan Acak Kelompok (RAK) pola faktorial yang terdiri atas dua faktor dengan tiga ulangan dan dua destruksi. Faktor pertama adalah komposisi media tumbuh $(\mathrm{C})$ yang terdiri atas: $100 \%$ zeolit (kontrol) (C0), $75 \%$ zeolit $+25 \%$ Arang sekam ( $3: 1 \mathrm{v} / \mathrm{v})(\mathrm{C} 1)$, $50 \%$ zeolit $+50 \%$ arang sekam (1:1 v/v) (C2), $25 \%$ zeolit $+75 \%$ arang sekam (1:3 v/v) (C3), dan $100 \%$ arang sekam (C4). Faktor kedua adalah FMA (M) yang terdiri atas: Glomus sp. (M1), Gigaspora sp. (M2), dan Glomus sp. + Gigaspora sp. (M3).

Bahan penelitian ini terdiri atas media zeolit dan bahan organik berupa arang sekam padi, yang ditimbang sesuai dengan perlakuan, kemudian dimasukkan ke dalam pot yang telah dilapisi plastik untuk mencegah hilangnya unsur hara yang diberikan dan mengurangi kontaminasi pada media.

Inokulan FMA yang digunakan berasal dari Laboratorium Biologi dan Bioteknologi Tanah Unpad yang berasal dari potongan akar Jarak (Jatropha sp.) terinfeksi yang terdiri atas dua jenis yaitu Glomus sp. dan Gigaspora sp. dengan kepadatan spora 700 spora per 20 gram. Spora fungi dipisahkan dari medianya dengan cara disaring dengan menggunakan saringan bertingkat berukuran $250 \mu \mathrm{m}, 125 \mu \mathrm{m}$ dan $45 \mu \mathrm{m}$ (metode penyaringan basah). Spora yang tersaring diamati di bawah mikroskop, kemudian dipisahkan berdasarkan jenis isolatnya (Glomus sp. dan Gigaspora sp.). Spora diambil sebanyak 10 buah spora untuk setiap isolat tunggal (Glomus sp. dan Gigaspora sp.), sedangkan untuk perlakuan campuran diambil masing-masing isolat sebanyak 5 buah spora kemudian dicampurkan.

Tanaman sorgum digunakan sebagai tanaman inang. Benih sorgum direndam dalam larutan klorok $2 \%$ selama 10 menit, diaduk dan dikocok hingga terkelupas kulit arinya, dan dibilias hingga bersih dengan air. Selanjutnya benih disemaikan dalam bak kecambah dengan menggunakan media zeolit yang bersih dan steril. Benih sorghum berkecambah pada umur 3-4 hari. Benih yang telah berkecambah tersebut pada umur 7 hari setelah tanam (HST) dipindahtanamkan ke dalam pot yang berisi media sesuai perlakuan sebanyak 2 tanaman per pot. Penyiraman dilakukan dengan larutan Hyponex Merah (25-5-20) dengan dosis $5 \mathrm{~g}$ per 10 liter dan diulang sebanyak dua kali sminggu selama 2,5-3 bulan (Prematuri \& Faiqoh, 1999). Penyiraman dihentikan dan dilakukan pengeringan (stressing) selama dua minggu sebelum dilakukan pemanenan. Selanjutnya bagian atas tanaman dipotong dan bagian akar tanaman diambil dan dibersihkan untuk dianalisis

Variabel yang diamati meliputi persentase akar terinfeksi, panjang akar, panjang akar terinfeksi, berat akar segar, nisbah pupus akar dan tinggi tanaman Sorgum. Semua variabel diamati pada 8 dan 12 minggu setelah tanam (MST), kecuali untuk nisbah pupus akar yang diamati pada 12 MST, sedangkan untuk tinggi tanaman diamati setiap dua minggu sekali. Analisis statistik dilakukan dengan menggunakan program Anova. Perlakuan dibandingkan dengan menggunakan uji $\mathrm{F} \quad 5 \%$ dilanjutkan dengan uji jarak berganda Duncan pada taraf $5 \%$.

\section{HASIL DAN PEMBAHASAN}

\section{Persentase Akar Terinfeksi}

Hasil analisis menunjukkan tidak terjadi interaksi antara perbandingan media (zeolit dan arang sekam) dengan FMA terhadap persentase infeksi akar. Pada Tabel 1 diketahui bahwa umur 8 MST perlakuan media zeolit $100 \%$ (C0) dan perlakuan zeolit $75 \%$ : arang sekam $25 \%$ (C1) berbeda nyata dengan perlakuan zeolit $25 \%$ : arang sekam $75 \%$ (C3). 
Tabel 1. Pengaruh mandiri perbandingan media dan fungi mikoriza arbuskula terhadap persentase infeksi akar

\begin{tabular}{|c|c|c|}
\hline \multirow{2}{*}{ Perlakuan } & \multicolumn{2}{|c|}{ \% Infeksi Akar } \\
\hline & 8 MST & 12 MST \\
\hline \multicolumn{3}{|l|}{ Perbandingan Media } \\
\hline C0 : zeolit $100 \%$ & $19 \mathrm{~b}(\mathrm{R})$ & $20 \mathrm{ab}(\mathrm{R})$ \\
\hline C1 : zeolit + arang sekam (75 \% : $25 \%)$ & $19 \mathrm{~b} \quad(\mathrm{R})$ & $36 \mathrm{~b} \quad(\mathrm{~S})$ \\
\hline C2 : zeolit + arang sekam (50 \% : $50 \%)$ & $11 \mathrm{ab}(\mathrm{R})$ & $42 \mathrm{~b} \quad(\mathrm{~S})$ \\
\hline C3 : zeolit + arang sekam (25\% : $75 \%)$ & 5 a (SR) & $46 \mathrm{~b} \quad(\mathrm{~S})$ \\
\hline C4 : arang sekam $100 \%$ & 7 ab (R) & 7 a $(\mathrm{R})$ \\
\hline
\end{tabular}

Fungi Mikoriza Arbuskula

$\begin{array}{llllll}\text { M1 : Glomus sp. } & 25 \text { a } & (\mathrm{R}) & 27 \text { a } & \text { (S) } \\ \text { M2 : Gigaspora sp. } & 25 \text { a } & (\mathrm{R}) & 29 & \text { a } & \text { (S) } \\ \text { M3 : Glomus sp + Gigaspora sp. } & 13 \text { a } & (\mathrm{R}) & 35 \text { a } & \text { (S) }\end{array}$

Keterangan: Nilai rata-rata yang diikuti huruf yang sama tidak berbeda nyata menurut uji Duncan $5 \%$. $\mathrm{SR}=$ sangat rendah, $\mathrm{R}=$ rendah, $\mathrm{S}=$ sedang, dan $\mathrm{T}$ = tinggi.

Tabel 2. Pengaruh mandiri komposisi media tumbuh dan fungi mikoriza arbuskula (FMA) terhadap nisbah pupus akar pada 12 MST.

\begin{tabular}{lccc}
\hline \multicolumn{1}{c}{ Perlakuan } & $\begin{array}{c}\text { Berat Pupus Segar } \\
(\mathbf{g})\end{array}$ & $\begin{array}{c}\text { Berat Akar Segar } \\
(\mathbf{g})\end{array}$ & NPA \\
\hline Komposisi Media & & & \\
C0: zeolit (kontrol) & 3,28 & 1,12 & $3,56 \mathrm{a}$ \\
C1 : zeolit + arang sekam (3:1) & 0,86 & 0,14 & $7,01 \mathrm{~b}$ \\
C2 : zeolit + arang sekam (1:1) & 0,57 & 0,13 & $5,81 \mathrm{ab}$ \\
C3 : zeolit + arang sekam (1:3) & 0,29 & 0,06 & $5,58 \mathrm{ab}$ \\
C4 : arang sekam & 0,01 & 0,01 & $1,07 \mathrm{a}$ \\
\hline Fungi Mikoriza Arbuskula (M) & & & \\
M1 : Glomus sp. & 0,82 & 0,19 & $4,42 \mathrm{a}$ \\
M2: Gigaspora sp. & 1,19 & 0,29 & $4,98 \mathrm{a}$ \\
M3: Glomus sp + Gigaspora sp. & 1,00 & 0,39 & $4,41 \mathrm{a}$ \\
\hline
\end{tabular}

Keterangan: Nilai rata-rata yang diikuti huruf yang sama tidak berbeda nyata menurut uji Duncan $5 \%$.

Pada 12 MST, komposisi media zeolit dan arang sekam (C1, C2 dan C3) menghasilkan persen infeksi akar berturut-turut sebesar $36 \%$, $42 \%$, dan $46 \%$ nyata lebih tinggi dibandingkan dengan arang sekam $100 \%(\mathrm{C} 4)$, namun tidak berbeda nyata dengan media zeolit $100 \%(\mathrm{C} 0)$.

Berbeda dengan perlakuan isolat FMA, pada 8 dan 12 MST tidak memberikan pengaruh yang nyata, namun secara keseluruhan telah terjadi peningkatan infeksi akar dari rendah menjadi sedang berdasarkan klasifikasi persen infeksi akar kriteria Rajapakse dan Miller (1992), yaitu Kelas $1(0-5 \%)=$ sangat rendah, Kelas $2(6-25 \%)=$ rendah, Kelas 3 $(26-50 \%)=$ sedang, Kelas $4(51-75 \%)=$ tinggi dan Kelas $5(76-100 \%)$ = sangat tinggi. Hal ini mengindikasikan telah terjadinya simbiosis antara akar tanaman inang dengan FMA yang cukup baik.

\section{Nisbah Pupus Akar}

Pada Tabel 2 terlihat pengaruh mandiri dari komposisi media tumbuh yang berpengaruh nyata terhadap nilai nisbah pupus akar (NPA). Pada media zeolit $100 \%$ menunjukkan nilai NPA yang lebih baik yaitu 3,56 karena lebih mendekati seimbang $(\approx 1)$, meskipun perlakuan arang sekam 100\% memiliki nilai 1,07 tetapi menunjukkan pertumbuhan yang kurang baik dilihat dari berat pupus dan akar segarnya yang sangat kecil. Namun demikian perlakuan ketiga isolat FMA baik yang diberikan secara tunggal maupun campuran (Glomus sp. + Gigaspora sp.) tidak berpengaruh nyata. 


\section{Tinggi Tanaman Sorgum}

Perlakuan zeolit (kontrol) sebagai media tumbuh mampu meningkatkan tinggi tanaman sorgum baik pada media yang diberi isolat Glomus sp., Gigaspora sp. maupun campuran keduanya dari umur 2 sampai dengan 12 MST, meskipun pada saat awal tanam pertumbuhannya sedikit lambat dibandingkan dengan perlakuan media lainnya. Perlakuan komposisi media zeolit dan arang sekam (C1, C2, dan C3) masih mampu meningkatkan tinggi tanaman sorgum walaupun lebih rendah dari zeolit (C0), namun lebih baik dibandingkan dengan perlakuan arang sekam saja (C4) (Tabel 3). meskipun tidak terjadi pengaruh yang nyata tetapi dapat dilihat dari peningkatan \% infeksi akar pada C2 dan C3 mengalami peningkatan 31\% dan $41 \%$ dari minggu ke-8 sampai minggu ke-12. Sedangkan menurut klasifikasi Rajapakse, pada media kombinasi (C1, C2 dan C3) dari 8 MST ke 12 MST mengalami peningkatan infeksi akar dari rendah ke sedang, hal ini mengindikasikan bahwa kombinasi media mampu menciptakan kondisi yang baik untuk pertumbuhan akar dan perkecambahan FMA sehingga terjadi proses simbiosis yang baik antara akar tanaman dengan FMA.

Rendahnya tingkat infeksi akar yang

Tabel 3. Pengaruh mandiri komposisi media tumbuh dan fungi mikoriza arbuskula (FMA) terhadap tinggi tanaman sorgum.

\begin{tabular}{lcccccc}
\hline \multirow{2}{*}{\multicolumn{1}{c}{ Perlakuan }} & \multicolumn{6}{c}{ Tinggi Tanaman $(\mathbf{c m})$ setiap } \\
\cline { 2 - 7 } & $\mathbf{2}$ & $\mathbf{4}$ & $\mathbf{6}$ & $\mathbf{8}$ & $\mathbf{1 0}$ & $\mathbf{1 2}$ \\
\hline Komposisi Media & & & & & & \\
C0 : zeolit (kontrol) & $8,7 \mathrm{a}$ & $16,9 \mathrm{ab}$ & $33,8 \mathrm{~b}$ & $49,7 \mathrm{c}$ & $57,4 \mathrm{c}$ & $62,2 \mathrm{c}$ \\
C1 : zeolit + arang sekam $(3: 1)$ & $10,2 \mathrm{ab}$ & $15,1 \mathrm{ab}$ & $24,8 \mathrm{~b}$ & $26,4 \mathrm{~b}$ & $27,9 \mathrm{~b}$ & $30,4 \mathrm{~b}$ \\
C2 : zeolit + arang sekam $(1: 1)$ & $12,1 \mathrm{~b}$ & $18,9 \mathrm{~b}$ & $27,1 \mathrm{~b}$ & $28,7 \mathrm{~b}$ & $29,3 \mathrm{~b}$ & $29,7 \mathrm{~b}$ \\
C3 : zeolit + arang sekam $(1: 3)$ & $12,4 \mathrm{~b}$ & $19,4 \mathrm{~b}$ & $25,2 \mathrm{~b}$ & $25,9 \mathrm{~b}$ & $26,9 \mathrm{~b}$ & $27,1 \mathrm{~b}$ \\
C4 : arang sekam & $10,9 \mathrm{ab}$ & $11,4 \mathrm{a}$ & $12,4 \mathrm{a}$ & $12,5 \mathrm{a}$ & $12,5 \mathrm{a}$ & $12,5 \mathrm{a}$ \\
\hline Fungi Mikoriza Arbuskula & & & & & & \\
M1 : Glomus sp. & $10,1 \mathrm{a}$ & $16,2 \mathrm{a}$ & $23,8 \mathrm{a}$ & $26,4 \mathrm{a}$ & $30,3 \mathrm{a}$ & $31,9 \mathrm{a}$ \\
M2: Gigaspora sp. & $10,9 \mathrm{a}$ & $15,6 \mathrm{a}$ & $24,6 \mathrm{a}$ & $30,2 \mathrm{a}$ & $32,2 \mathrm{a}$ & $33,2 \mathrm{a}$ \\
M3: Glomus sp + Gigaspora sp & $11,5 \mathrm{a}$ & $17,2 \mathrm{a}$ & $25,5 \mathrm{a}$ & $28,7 \mathrm{a}$ & $29,3 \mathrm{a}$ & $30,8 \mathrm{a}$ \\
\hline
\end{tabular}

Keterangan: Nilai rata-rata yang diikuti huruf yang sama tidak berbeda nyata menurut uji Duncan $5 \%$.

Berbeda dengan perlakuan FMA yang tidak memberikan pengaruh yang nyata terhadap tinggi tanaman sorgum, ketiga isolat FMA diketahui memiliki kemampuan yang sama dalam meningkatkan pertumbuhan tanaman seperti terlihat pada Tabel 3.

Infeksi akar merupakan bentuk awal dari proses simbiosis antara FMA dengan akar tanaman inang (Chalimah, et al., 2007). Pada media zeolit $100 \%$ (C1) persentase infeksi akar tidak berbeda nyata dengan media kombinasi (zeolit: arang sekam), meskipun termasuk rendah dibandingkan dengan media kombinasi yang memiliki \% infeksi sedang berdasarkan klasifikasi \% infeksi akar Rajapakse, S. \& Miller, (1992). Variabel lainnya, seperti tinggi tanaman sorgum pada media zeolit $100 \%$ ini menunjukkan hasil terbaik dibandingkan dengan perlakuan media lainnya. Sehingga zeolit masih lebih baik untuk dijadikan carrier inokulan FMA.

Pada media kombinasi (C1, C2 dan C3), dihasilkan dari spora tunggal maupun campuran pada saat 8 MST diduga dari inokulan spora yang diinokulasikan tidak seluruhnya berkecambah, sehingga hifa-hifa yang menginfeksi akar menurun karena masing-masing spora FMA membutuhkan waktu yang berbeda untuk berkecambah. Selain itu, faktor lain yang mempengaruhi infeksi akar adalah jenis inokulan, eksudat akar dan faktor lingkungan (Chalimah, et al. 2007), serta spesies tanaman inangnya (Trisilawati \& Cecep, 2003). Lain halnya pada saat 12 MST yang menghasilkan persen infeksi akar yang lebih tinggi dari pada 8 MST. Seperti yang diutarakan Bertham (2003), bahwa proses sporulasi (perkecambahan spora) pada umumnya terjadi pada saat minggu ke- 4-8 setelah pengkulturan.

Dilihat dari nilai nisbah pupus akar (NPA), media zeolit $100 \%$ menunjukkan nilai yang lebih baik karena mendekati seimbang (mendekati 1), artinya pertumbuhan tanaman baik, dilihat dari 
perbandingan berat akar dan tajuk yang mendekati seimbang. Hal ini diduga bahwa pada media zeolit, proses penyerapan unsur hara lebih mudah dijangkau oleh perakaran tanaman karena zeolit bersifat porus dan mampu menyerap kelebihan air yang diberikan dan melepaskannya kembali pada saat dibutuhkan tanaman. Meskipun nilai NPA pada media arang sekam bernilai 1,07 akan tetapi tidak memperlihatkan pertumbuhan tanaman yang baik. Hal ini terjadi karena pada media arang sekam $100 \%$ terlalu porus sehingga daya menahan air semakin berkurang (Dhalimi, 2003), sehingga kondisi media sangat lembab dan sebagain akar tanaman mengalami pembusukan.

Berdasarkan hasil analisis kimia media tumbuh (data tidak dilampirkan) diketahui bahwa nilai KTK arang sekam padi $\left(88,08 \mathrm{cmol} \mathrm{kg}^{-1}\right)$ lebih tinggi dibandingkan dengan zeolit $67,60 \mathrm{cmol} \mathrm{kg}^{-1}$. Hal ini berpengaruh terhadap proses penjerapan air dan unsur hara, karena pada media arang sekam akan lebih banyak menjerap air yang mengakibatkan media lebih lembab dan basah, sehingga sirkulasi udara terhambat dan mengakibatkan pembusukkan pada akar tanaman. Selanjutnya, pertumbuhan tanaman pun akan terhambat.

Tidak berbedanya antara inokulasi tunggal maupun campuran dari penelitian ini terhadap pertumbuhan tinggi tanaman, berbeda dengan pendapat Pelealu (2007) yang menyatakan bahwa isolat campuran yang terdiri dari Glomus, Acaulospora dan Gigaspora mampu meningkatkan pertumbuhan tanaman dibandingkan FMA dari jenis tunggal yang diaplikasikan pada tanaman sorgum varietas Mandau.

Pada variabel tinggi tanaman jelas terlihat dari peningkatan tinggi tanaman pada saat umur tanaman 8 sampai dengan 12 MST, komposisi campuran media zeolit dan arang sekam (C1, C2, dan C3) masih mampu meningkatkan tinggi tanaman sorgum walaupun lebih rendah dari zeolit (C0), namun lebih baik dibandingkan dengan perlakuan arang sekam saja (C4). Diduga terdapat faktor lain yang mempengaruhi pertumbuhan tanaman, seperti yang diutarakan Faiqoh (2007) bahwa kondisi lingkungan dapat mempengaruhi pertumbuhan tanaman yang terdiri atas $\mathrm{pH}$ media tumbuh, $\mathrm{pH}$ air penyiraman, frekwensi dan volume penyiraman, serta temperatur dan lama penyinaran. Mengingat $\mathrm{pH}$ media tumbuh yang semakin rendah (data tidak dilampirkan) selama pertumbuhan tanaman diduga memberikan pengaruh terhadap perkembangan mikoriza dan tanaman sorgum.

\section{SIMPULAN}

Selain media zeolit, arang sekam dapat dijadikan media pembawa inokulan FMA, namun penggunaannya masih harus dikombinasikan dengan zeolit, yaitu $75 \%$ zeolit : $25 \%$ arang sekam atau $50 \%$ zeolit : $50 \%$ arang sekam. Arang sekam $100 \%$ belum dapat dijadikan sebagai media (carrier) inokulan FMA, karena media tersebut terlalu porus sehingga perlu dilakukan pengaturan pemberian air siraman atau air nutrisi agar tidak terjadi pengendapan dan pembusukan di bagian bawah media. Ditinjau dari jenis isolat FMA, baik Glomus sp., Gigaspora sp., maupun kombinasi keduanya memperlihatkan hasil yang tidak berbeda nyata dari semua parameter yang diukur. Dengan demikian, penggunaan media zeolit dan arang sekam ini dapat digunakan untuk semua jenis isolat FMA.

\section{DAFTAR PUSTAKA}

Abdullah, S, Y Musa dan Feranita. 2005. Perbanyakan cendawan mikoriza arbuskular (CMA) pada berbagai varietas jagung (Zea mays. L.) dan pemanfaatannya pada dua varietas tebu (Saccharum officinarum L.). Jurnal Sains dan Teknologi. 5: 12-20.

Bertham, YH. 2003. Teknik Pemurnian biakan monoxonic CMA dengan Metode cawan petri dan tabung reaksi. Jurnal Ilmu-ilmu Pertanian Indonesia. 5: 18-26.

Brundrett, MN, B. Bougher, TG Dell and N. Malayczuk. 1996. Working with Mycorrhizas in forestry and agriculture. ACIAR Monograph 32. Australian Centre for International Agricultural Research, Canberra.

Chalimah, S, Muhadiono, L Aznam, S Haran dan N Toruan. 2007. Perbanyakan Gigaspora sp. dan Aclauspora sp. dengan kultur pot di rumah kaca. Biodiversitas 7: 12-19.

Departemen Pertanian. 1990. Teknologi Budidaya Sorgum. Balai Informasi Pertanian Provinsi Irian Jaya, Jayapura.

Departemen Pertanian. 2001. Zeolit untuk pertanian. Lembar Informasi Pertanian No. 15 Seri: Tanaman Pangan/2001/djs Agdex: 530. Jawa Barat, Bandung.

Dhalimi, A. 2003. Pengaruh sekam dan abu sekam terhadap pertumbuhan dan kematian tanaman panili (Vanilla Planifolia Andrews) di Pembibitan. Buletin TRO 14: 1-12. 
Faiqoh. 2007. Metoda Dasar Bekerja dengan Mikoriza Arbuskula. Laboratorium Bioteknologi Hutan dan Lingkungan, Pusat Penelitian Sumberdaya Hayati dan Bioteknologi Institut Pertanian Bogor, Bogor.

Gunawan, AW. 1999. Teknik pembuatan kultur cendawan mikoriza arbuskula. Makalah Workshop Mikoriza "Aplikasi Cendawan Mikoriza pada Tanaman Pertanian, Perkebunan dan Kehutanan”. Asosiasi Mikoriza Indonesia, Bogor.

Nurbaity, A., D. Herdiyantoro, dan O. Mulyani. 2009. Pemanfaatan Jerami dan Arang Sekam sebagai Bahan Pembawa Inokulan Mikoriza Arbuskula. Jurnal Biologi Vol. XIII No.1.

Pelealu, JJ. 2007. Biofertilisasi Mikoriza VasikularArbuskular dan Pupuk Organik pada Sorgum (Sorgum bicolor, L Moench) di Lahan Marjinal Perkebunan Kelapa (Cocos nucifera, L). Universitas Airlangga, Surabaya.

Prematuri, R dan N Faiqoh. 1999. Produksi Inokulum Cendawan Mikoriza Arbuskula. Laboratorium Bioteknologi Hutan, PAU Bioteknologi IPB. Makalah Workshop Mikoriza “Aplikasi Cendawan Mikoriza pada Tanaman Pertanian, Perkebunan dan Kehutanan". Asosiasi Mikoriza Indonesia, Bogor. 27 September - 2 Oktober 1999.

Rajapakse, S dan JC. Miller Jr. 1992. Methods for studying vesicular-arbuscular mycorrhizal root colonization and related root physical properties. Methods in Microbiol 24: 302316.

Rao, N.S.S. 1994. Mikroorganisme Tanah dan Pertumbuhan Tanaman. Terjemahan $\mathrm{H}$. Susilo. Universitas Indonesia Press, Jakarta.

Setiadi, Y. 1999. Pengembangan CMA sebagai pupuk hayati dalam bidang kehutanan. makalah workshop mikoriza. AMI, Bogor. 27 September - 2 Oktober 1999.

Simanungkalit. 2003. Teknologi cendawan mikoriza arbuskuler: produksi inokulan dan pengawasan mutunya. Makalah Seminar Mikoriza. AMI, Bandung. 16 September 2003.

Sirappa, MP 2003. Prospek pengembangan Sorgum di Indonesia Sebagai Komoditas Alternatif Untuk Pangan, Pakan, dan Industri. Jurnal Litbang Pertanian 22:133-140.

Smith, SE and DJ Read 1997. Mycorrhizal Symbiosis. Academic Press. Harcourt Brace \& Company, Publishers, San Diego.

St. John, TV, DC Coleman and CPP Reid. 1983. Association of Vesicular Arbuscular Mycorrhizal Hyphae with Soil Organic Particles. Ecology. 64: 957-959.

Trisilawati, O dan C Firman. 2004. Pengaruh fungi mikoriza arbuskula terhadap pertumbuhan bibit panili (vanilla planifolia andrews). balai penelitian Tanaman Rempah dan Obat Cimanggu, Bogor. Buletin TRO 15: 19-24. 